PREPARED FOR THE U.S. DEPARTMENT OF ENERGY, UNDER CONTRACT DE-AC02-76CH03073

PPPL-3885

PPPL-3885

UC-70

Coil Tolerance Impact on Plasma Surface Quality for NCSX

by

Art Brooks and Wayne Reiersen

October 2003

$\left.\stackrel{M}{M}\right|_{\substack{\text { PRInCETON PLASIMA } \\ \text { PHYSICS LABORATORY }}} ^{D}$

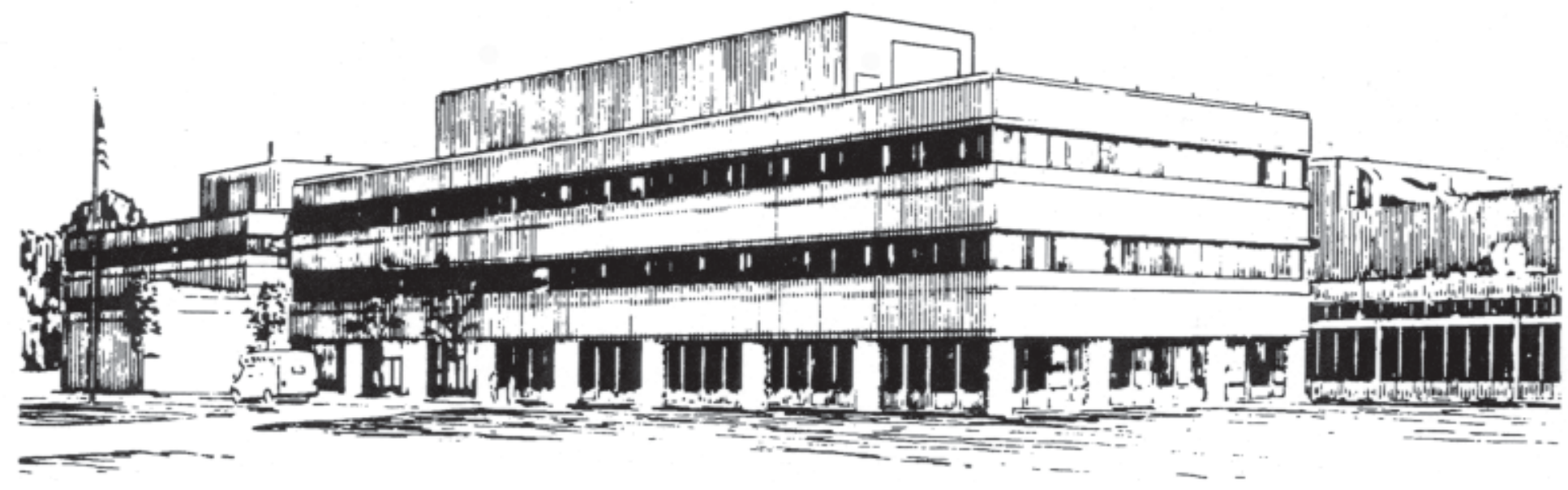

PRINCETON PLASMA PHYSICS LABORATORY PRINCETON UNIVERSITY, PRINCETON, NEW JERSEY 


\section{PPPL Reports Disclaimer}

This report was prepared as an account of work sponsored by an agency of the United States Government. Neither the United States Government nor any agency thereof, nor any of their employees, makes any warranty, express or implied, or assumes any legal liability or responsibility for the accuracy, completeness, or usefulness of any information, apparatus, product, or process disclosed, or represents that its use would not infringe privately owned rights. Reference herein to any specific commercial product, process, or service by trade name, trademark, manufacturer, or otherwise, does not necessarily constitute or imply its endorsement, recommendation, or favoring by the United States Government or any agency thereof. The views and opinions of authors expressed herein do not necessarily state or reflect those of the United States Government or any agency thereof.

\section{Availability}

This report is posted on the U.S. Department of Energy's Princeton Plasma Physics Laboratory Publications and Reports web site in Fiscal Year 2004. The home page for PPPL Reports and Publications is: http://www.pppl.gov/pub_report/

DOE and DOE Contractors can obtain copies of this report from:

U.S. Department of Energy

Office of Scientific and Technical Information

DOE Technical Information Services (DTIS)

P.O. Box 62

Oak Ridge, TN 37831

Telephone: (865) 576-8401

Fax: (865) 576-5728

Email: reports@adonis.osti.gov

This report is available to the general public from:

National Technical Information Service

U.S. Department of Commerce

5285 Port Royal Road

Springfield, VA 22161

Telephone: $1-800-553-6847$ or

(703) $605-6000$

Fax: (703) 321-8547

Internet: http://www.ntis.gov/ordering.htm 


\title{
Coil Tolerance Impact on Plasma Surface Quality for NCSX
}

\author{
Art Brooks and Wayne Reiersen \\ Princeton Plasma Physics Lab
}

\begin{abstract}
The successful operation of the NCSX machine will require producing plasma configurations with good flux surfaces, with a minimum volume of the plasma lost to magnetic islands or stochastic regions. The project goal is to achieve good flux surfaces over $90 \%$ of the plasma volume. NCSX is a three period device designed to be operated with iota ranging from $\sim 0.4$ on axis to $\sim 0.7$ at the edge. The field errors of most concern are those that are resonant with $3 / 5$ and $3 / 6$ modes (for symmetry preserving field errors) and the $1 / 2$ and $2 / 3$ modes (for symmetry breaking field errors). In addition to losses inherent in the physics configuration itself, there will be losses from field errors arising from coil construction and assembly errors. Some of these losses can be recovered through the use of trim coils or correction coils. The impact of coil tolerances on plasma surface quality is evaluated herein for the NCSX design. The methods used in this evaluation are discussed. The ability of the NCSX trim coils to correct for field errors is also examined. The results are used to set coils tolerances for the various coil systems.
\end{abstract}

\section{INTRODUCTION}

Coil Tolerances, or more generally, the departure of the Coil Geometry from their design, is expected to be one of the largest sources of magnetic field errors for the National Compact Stellarator Experiment (NCSX). The as-built geometry may differ not only in size, location and orientation, but in shape as well. Even small differences in geometry can lead to field errors which, if resonant at the plasma, produce magnetic islands or stochastic regions that destroy the plasma surface quality and degrade machine performance. Section II describes the general analytical methods used to evaluate the impact of field errors from any source on the NCSX plasma. Section III examines a number of potential geometric perturbations that might be expected during the fabrication and assembly of the field coils and attempts to bound the problem. Section IV demonstrates the ability and limitations of the in-vessel trim and ex-vessel correction coils to mitigate the impact of geometry perturbations which, if left unchecked, would result in severe degradation of the plasma.

\section{ANALYSIS METHODS}

The impact of Field Errors are traditionally investigated for vacuum field configurations by examining Poincare plots from field line tracing for any source and observing induced islands or changes in islands with respect to a Poincare plot for an ideal configuration. For NCSX operating with significant plasma current and beta, the field from the plasma must be included to achieve the iota profiles expected which cross the resonances of concern. The PIES[1] code can be used to produce Poincare plots which are self consistent and indeed is being used for necessarily limited investigations within the NCSX Physics Group. The long run times required for convergence make PIES a difficult design tool to employ for general engineering use.

A simpler approach was taken to provide a first cut at field error source assessment. It is based on the analytic expression for magnetic island width, in flux coordinates, produced by magnetic field perturbations in a general toroidal stellarator geometry [2]. It presumes the underlying (perturbation free) field contains nested magnetic surfaces and is valid for rational surfaces (where the rotational transform $\mathrm{l}=\mathrm{n} / \mathrm{m}$ ). The VMEC[3] equilibrium provides such a field. (Alternately, a vacuum configuration with the same rotational transform profile as the LI383 full current, full beta configuration could be used. However, attempts to define such a configuration were not successful.) Use of the VMEC equilibrium simplifies the evaluation of the island width which depends on $\mathrm{B}^{\mathrm{s}} / \mathrm{B}^{\phi}$ expressed in straight line (magnetic) coordinates. The following presents the method used.

Using s, $\theta, \phi$ as the magnetic coordinates, island width given by :

$$
d s=4\left|\frac{C_{m n}(s)}{m \iota^{\prime}(s)}\right|^{1 / 2}
$$

where $C(s) \equiv \frac{B^{s}}{B^{\phi}}=\frac{B \bullet \nabla s}{B \bullet \nabla \phi}$

$\frac{B^{s}}{B^{\phi}}$ is evaluated by making use of

$$
\begin{aligned}
B^{\phi} & =\frac{1}{J_{s, \theta, \phi}} \frac{d \Psi}{d s} \\
\text { and } \quad \nabla s & =\frac{1}{J_{s, \theta, \phi}}\left(\frac{\partial R}{\partial \theta} \times \frac{\partial R}{\partial \phi}\right)
\end{aligned}
$$

leaving an expression which does not require explicit evaluation of the Jacobian and is linear in B (and therefore coil currents)

$$
\frac{B^{s}}{B^{\phi}}=\frac{B \cdot\left(\frac{\partial R}{\partial \theta} \times \frac{\partial R}{\partial \phi}\right)}{\frac{d \Psi}{d s}}
$$

A computer program called VACISLD was written to evaluate the island width using the VMEC field and a perturbation field generated by coil filaments or alternately supplied as a field map from other sources. A field line tracing routine called TraceBrtp, capable of tracing the perturbation field with the VMEC field in VMEC coordinates, was developed to examine both symmetric and symmetry breaking field perturbations. VACISLD and TraceBrtp were benchmarked against PIES* for symmetry preserving field perturbations 
(*PIES was modified by Don Monticello to allow adding a perturbation field from coils to the background VMEC field). Fig. 1 shows the resonances targeted.
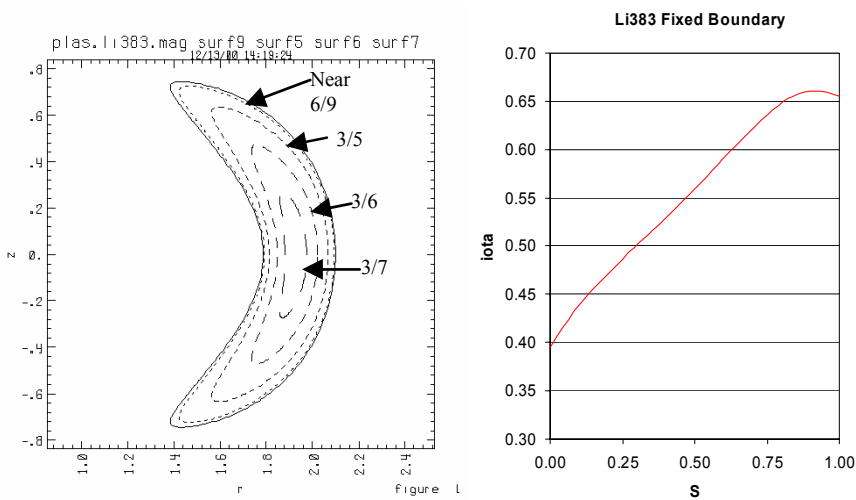

Fig 1 LI383 Plasma Configuration (left) with resonant surfaces and corresponding iota profile (right).

\section{Coil Geometric Perturbations InVEstigAted}

The accuracy to which we can fabricate and assemble the field coils represents probably the biggest concern for field errors. It also posed a large challenge in how to assess and evaluate these inherent uncertainties beforehand.

The experience gained from the stellarator community in the construction of past machines suggested tolerances on the order of one in a thousand as installed were achievable, though not necessarily cheaply. Applying this to NCSX with a major radius of $\sim 1.5 \mathrm{~m}$ would say tolerances of $+/-1.5 \mathrm{~mm}$ could be obtained. Subsequent discussions with potential manufacturers and construction groups have reassured us. The question remained whether this is adequate from a field error viewpoint.

To explore the impact of coil tolerances or more generally, the impact of geometric changes to the coil windings, a large number of potential coil distortions were examined using the methods described in Section II.

First, to try and reflect fabrication tolerances, systematic perturbations were applied to each degree of freedom describing the coil geometry. This was done for both the individual coil types (ie modular coil type A, B and C, TF 1,2 $\& 3$ and PF 1 thru 6) and the coil systems collectively. The perturbations were sinusoidal variations (where the mode number and phase of the variation were also varied) in $r, \theta$ and z. A coil set containing the perturbed geometry has combined with a coil set of opposite current of the unperturbed geometry, resulting in a coil set which provided only the differential field (ie error field) which could be evaluated against the VMEC fixed or free boundary equilibrium background field. For each geometric perturbation applied, an evaluation of the magnetic island size induced at each (significant) resonant surface in the plasma was made. A large number of cases where examined to cover the different coils and groups of coils, degree of freedom, mode and phase of perturbation. The results shown in Table I are the worse cases found for each coil type taken individually and collectively.

TABLE 1

Impact of Systematic Perturbations of Coil Distortion And Assembly on Islands Size, IN \% Total FluX

\begin{tabular}{|c|c|c|c|c|c|c|c|c|c|c|}
\hline & \multicolumn{3}{|c|}{$\begin{array}{c}\text { Coil } \\
\text { Distortion }\end{array}$} & & & \multicolumn{3}{|c|}{$\begin{array}{c}\text { Coil } \\
\text { Assembly }\end{array}$} & \multicolumn{2}{|r|}{ Island } \\
\hline & Phase & Mode & DOF & Size & Resonance & Phase & Mode & DOF & Size & Resonance \\
\hline All Modular & $\cos$ & 3 & $\mathrm{dt}$ & $13.4 \%$ & $3 / 5$ & $\cos$ & 2 & $\mathrm{dz}$ & $18.7 \%$ & $1 / 2$ \\
\hline Modular 1 & $\sin$ & 2 & $\mathrm{dt}$ & $15.7 \%$ & $1 / 2$ & - & - & $\mathrm{dz}$ & $6.9 \%$ & $1 / 2$ \\
\hline Modular 2 & $\cos$ & 2 & $\mathrm{dt}$ & $12.6 \%$ & $1 / 2$ & - & - & $\mathrm{dz}$ & $9.9 \%$ & $1 / 2$ \\
\hline Modular 3 & $\cos$ & 2 & $\mathrm{dt}$ & $11.6 \%$ & $1 / 2$ & - & - & $\mathrm{rt}$ & $8.3 \%$ & $1 / 2$ \\
\hline All TF & $\cos$ & 1 & $\mathrm{dt}$ & $1.0 \%$ & $3 / 5$ & $\sin$ & 1 & $\mathrm{rr}$ & $2.7 \%$ & $1 / 2$ \\
\hline $\mathrm{TF} 1$ & $\sin$ & 2 & $\mathrm{dt}$ & $3.1 \%$ & $1 / 2$ & - & - & $\mathrm{rr}$ & $3.3 \%$ & $1 / 2$ \\
\hline TF 2 & $\cos$ & 2 & $\mathrm{dt}$ & $2.7 \%$ & $1 / 2$ & - & - & $\mathrm{rr}$ & $2.5 \%$ & $1 / 2$ \\
\hline TF 3 & $\cos$ & 2 & $\mathrm{dt}$ & $2.6 \%$ & $1 / 2$ & - & - & $\mathrm{dt}$ & $2.1 \%$ & $1 / 2$ \\
\hline PF1 & $\sin$ & 1 & $\mathrm{dz}$ & $3.7 \%$ & $1 / 2$ & - & - & ry & $3.7 \%$ & $1 / 2$ \\
\hline PF2 & $\sin$ & 1 & $\mathrm{dz}$ & $2.8 \%$ & $1 / 2$ & - & - & ry & $2.8 \%$ & $1 / 2$ \\
\hline PF3 & $\sin$ & 1 & $\mathrm{dz}$ & $2.8 \%$ & $1 / 2$ & - & - & rx & $2.8 \%$ & $1 / 2$ \\
\hline PF4 & $\sin$ & 1 & $\mathrm{dz}$ & $3.9 \%$ & $1 / 2$ & - & - & rx & $3.9 \%$ & $1 / 2$ \\
\hline PF5 & $\sin$ & 1 & $\mathrm{dr}$ & $2.9 \%$ & $1 / 2$ & - & - & dy & $2.9 \%$ & $1 / 2$ \\
\hline PF6 & $\sin$ & 1 & $\mathrm{dz}$ & $2.3 \%$ & $1 / 2$ & - & - & ry & $2.3 \%$ & $1 / 2$ \\
\hline
\end{tabular}

Second, to try and reflect assembly tolerances, again freedom describing the coil position and orientation (ie free systematic perturbations were applied to each degree of body displacements). Again the effect on individual coil types 
and coil systems collectively were explored. The degree of freedom changes where done relative to a local coordinate system at the center of gravity of the coil. Rotation magnitudes were chosen to limit the maximum displacement at the coil to the specified tolerance. (Note: Some of the initial work contained herein reflected an earlier $2.0 \mathrm{~mm}$ tolerance instead the present $1.5 \mathrm{~mm}$ )

Examination of the impact of these various individual perturbations showed significant variation in their impact on island size. The most significant for each coil type is shown in Table I.

To try to assess how these different perturbations from fabrication and assembly might combine, a method was devised to combine them in a random fashion. A random factor was applied to coordinate change resulting from each combination of different coils and groups of coils, degree of freedom, mode and phase of perturbation. The individual coordinate changes were then summed and the resultant coordinate changes (now effectively a random function) normalized to the $1.5 \mathrm{~mm}$ tolerance specified. (This assumes the stackup of tolerances from all sources will be such as to assure the final location of every point in every coil is within $+/-1.5 \mathrm{~mm})$ A large number of random functions were examined $(\sim 200$ for each tolerance scheme) and the distribution of island sizes observed. Results tabulated in the table II show the range of islands that may be expected.
The impact of the magnitude of the coil tolerances was also investigated in an attempt to simplify - ie reduce cost of fabricating the coils. This was examined by redoing the random function studies varying the tolerance values for each of the coil systems (Modular, TF and PF) and within the Modular Coils. It was shown that tolerance control on the modular coils is most critical for regions of the coils that are in close proximity to the plasma, but could possibly be relaxed in regions far from the plasma. It was also shown that the tolerance of the TF and PF could be relaxed without significantly impacting field errors. Again, keep in mind that in all cases, the field errors would be intolerable without the use of trim/correction coils. The real question is how good are the trim/correction coils, in terms of how large a field error they can correct without damaging or otherwise altering the plasma configuration.

Other forms of geometric perturbations in addition to sinusoidal and random fourier functional distributions were investigated but not included here due to space limitations. These included local perturbations (ie'wavelet' type) and broad deformations (ie large regions of the coils perturbed in the same fashion) for which results were less severe than those reported here.

TABLE II

IMPACT OF TOLERANCE SCHEME ON ISLAND SIZE, IN \% TOTAL FLUX

\begin{tabular}{cccccccccl}
\hline Tolerance & mm & $\begin{array}{l}\text { Resonanc } \\
\text { e }\end{array}$ & $3 / 5$ & $6 / 10$ & $3 / 6$ & $1 / 2$ & $2 / 4$ & Totals & Comments \\
\hline Modular & 1.5 & Max & 6.1 & 1.4 & 2.5 & 16.4 & 5.1 & 22.1 & Correctable, ie - \\
TF & 1.5 & Min & 1.2 & 0.2 & 0.4 & 3.6 & 0.9 & 7.3 & Islands can be suppressed \\
PF & 1.5 & Avg & 3.7 & 0.8 & 1.5 & 9.9 & 3.2 & 13.9 & using correction coils \\
& & Std dev & 1.0 & 0.2 & 0.4 & 2.5 & 0.9 & 2.6 & to acceptable levels \\
& & & & & & & & & \\
Modular & 1.5 & Max & 6.1 & 1.4 & 2.5 & 16.6 & 5.1 & 22.2 & TF \& PF Tolerance \\
TF & 3.0 & Min & 1.5 & 0.3 & 0.4 & 3.4 & 1.1 & 7.1 & Has negligible impact \\
PF & 3.0 & Avg & 3.7 & 0.8 & 1.5 & 10.0 & 3.2 & 13.9 & on overall results \\
& & Std dev & 1.0 & 0.2 & 0.4 & 2.6 & 0.8 & 2.7 & (still correctable) \\
& & & & & & & & & \\
Modular & $1.5-3.0$ & Max & 6.6 & 1.5 & 2.5 & 19.1 & 5.4 & 24.3 & Softening Mod Tolerance \\
TF & 3.0 & Min & 1.1 & 0.3 & 0.4 & 3.0 & 1.2 & 7.4 & away from plasma \\
PF & 3.0 & Avg & 3.9 & 0.9 & 1.5 & 11.1 & 3.3 & 15.2 & has small impact \\
& & Std dev & 1.0 & 0.2 & 0.4 & 2.8 & 0.9 & 2.8 & (still correctable) \\
& & & & & & & & & Softening Mod Tolerance \\
Modular & 3.0 & Max & 8.7 & 2.1 & 3.5 & 23.2 & 7.2 & 31.2 & everywhere \\
TF & 3.0 & Min & 1.7 & 0.3 & 0.6 & 5.1 & 1.2 & 10.3 & (not sizeable impact \\
PF & 3.0 & Avg & 5.2 & 1.2 & 2.1 & 14.1 & 4.5 & 19.6 & \\
& & Std dev & 1.4 & 0.3 & 0.6 & 3.6 & 1.2 & 3.7 & (notrectable) \\
\end{tabular}




\section{FIELD ERROR MitigATION}

What should be clear is that even at these tight tolerances, the islands produced from either systematic or random distributions of coil geometry errors are potentially very damaging, possibly exceeding $20 \%$ of total flux in plasma. This would be unacceptable without some form of mitigation.

A set of in-vessel trim coils was previously designed to handle symmetry preserving corrections, targeting the $3 / 5(\mathrm{~m}=5)$ and $3 / 6(\mathrm{~m}=6)$ resonances. Another set of ex-vessel correction coils was introduced to target lower order, non-symmetric resonances $(1 / 2,2 / 4,2 / 3$, etc). These are pictured in the fig. 3 and fig. 4 below.

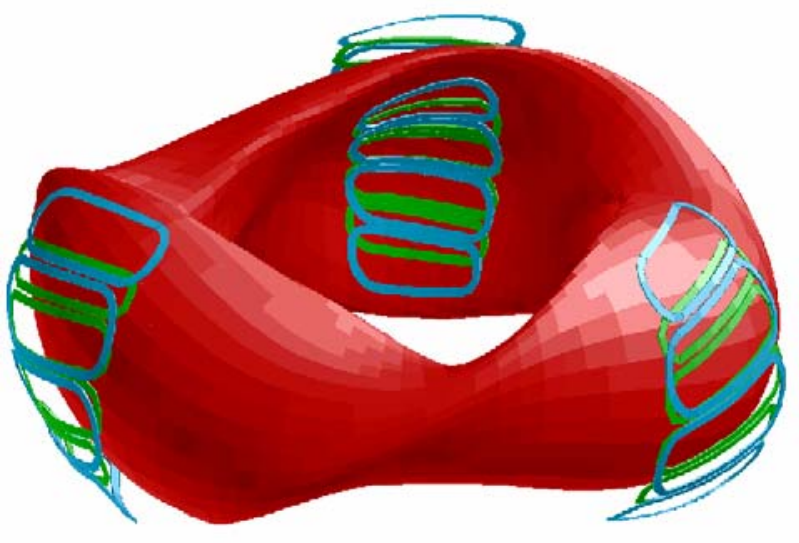

Fig. 3 In-Vessel Trim Coils, $m=5$ (upper layer) and $m=6$ (lower layer) used to control the dominate $3 / 5$ and $3 / 6$ modes shown in proximity to the LI383 plasma
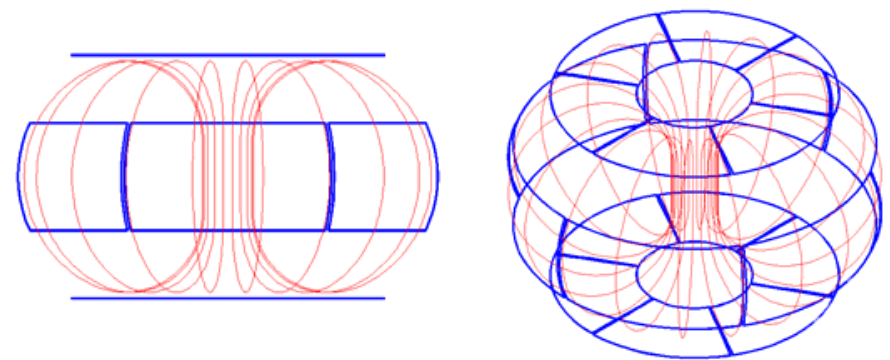

Fig. 4 Ex-Vessel Correction Coils used from controlling low order resonant modes shown outside the TF coils.

To demonstrate their effectiveness in island mitigation, a number of the more severe cases of islands induced from coil geometric perturbations were examined. For each case, currents in each of the trim or correction coils need to be solved for to attempt to suppress the islands without undue damage to the plasma boundary or exciting other resonances. A coupling matrix (A) was calculated which related unit currents in each of the trim/correction coils to impact on the resonant field component for each resonance. A target vector (b) was formed of the resonances induced by the coil geometry perturbation that we are trying to suppress. The trim/correction coil current vector (x) is obtained by solving $\mathbf{A x}=\mathbf{b}$ using a SVD (single value decomposition) algorithm. The TraceBrtp code described earlier was used to visualize the field structure before and after the applied correction. Results, shown in the fig. 5 , indicate even for the worse case stackups at $1.5 \mathrm{~mm}$ tolerance, the total flux lost to islands can be reduced to an acceptable level without undue perturbations to the plasma boundary, and acceptable current levels in the trim/correction coils.

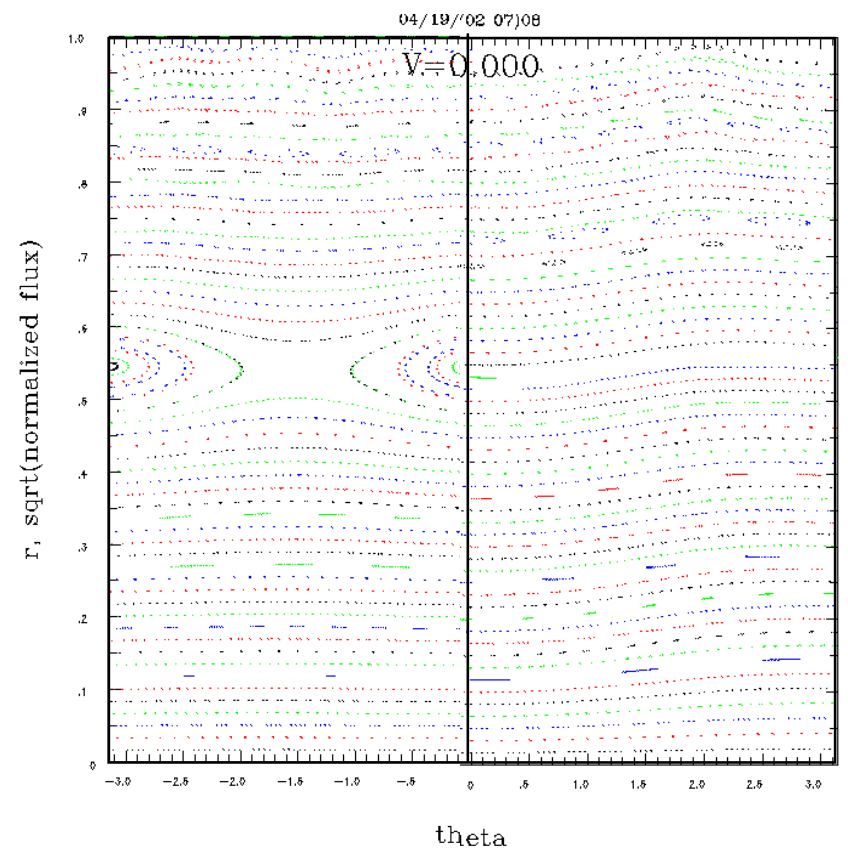

Fig. $5 \mathrm{M}=2$ Symmetric Islands from Worst Case (Modular Coil 1) Distortion (Left Half) Compared to Island Suppression Using Correction Coils requiring a maximum current of 63 KAT (Right Half)

\section{CONClusions}

The methods presented herein have provided a means to examine the impact of a large number of potential coil geometry perturbations, to identify those that are most significant, and set coil tolerances accordingly. While it is clear that if left unchecked even tight coil tolerances would still leave damaging islands, the system of trim and correction coils is robust enough to mitigate the worse cases found.

\section{ACKNOWLEDGMENT}

The authors are grateful to S.P. Hirshman and D. Monticello and other members of the NCSX team for their many discussions in the development of the methods used herein. This work was supported by the United States Department of Energy Contract No. DE-AC02-76-CHO-3073

\section{REFERENCES}

[1] A.H. Reiman and H.S. Greenside, Comput. Phys. Commun. 43, 157 (1986)

[2] D.K. Lee, J.H. Harris, G.S. Lee, Nuclear Fusion, Vol. 30, No. 10 (1990)

[3] S.P. Hirshman and J.C. Whitson, Phys. Fluids 26 (1883) 3533 


\section{External Distribution}

Plasma Research Laboratory, Australian National University, Australia

Professor I.R. Jones, Flinders University, Australia

Professor João Canalle, Instituto de Fisica DEQ/IF - UERJ, Brazil

Mr. Gerson O. Ludwig, Instituto Nacional de Pesquisas, Brazil

Dr. P.H. Sakanaka, Instituto Fisica, Brazil

The Librarian, Culham Laboratory, England

Mrs. S.A. Hutchinson, JET Library, England

Professor M.N. Bussac, Ecole Polytechnique, France

Librarian, Max-Planck-Institut für Plasmaphysik, Germany

Jolan Moldvai, Reports Library, Hungarian Academy of Sciences, Central Research Institute for Physics, Hungary

Dr. P. Kaw, Institute for Plasma Research, India

Ms. P.J. Pathak, Librarian, Institute for Plasma Research, India

Ms. Clelia De Palo, Associazione EURATOM-ENEA, Italy

Dr. G. Grosso, Instituto di Fisica del Plasma, Italy

Librarian, Naka Fusion Research Establishment, JAERI, Japan

Library, Laboratory for Complex Energy Processes, Institute for Advanced Study, Kyoto University, Japan

Research Information Center, National Institute for Fusion Science, Japan

Dr. O. Mitarai, Kyushu Tokai University, Japan

Dr. Jiangang Li, Institute of Plasma Physics, Chinese Academy of Sciences, People's Republic of China

Professor Yuping Huo, School of Physical Science and Technology, People's Republic of China

Library, Academia Sinica, Institute of Plasma Physics, People's Republic of China

Librarian, Institute of Physics, Chinese Academy of Sciences, People's Republic of China

Dr. S. Mirnov, TRINITI, Troitsk, Russian Federation, Russia

Dr. V.S. Strelkov, Kurchatov Institute, Russian Federation, Russia

Professor Peter Lukac, Katedra Fyziky Plazmy MFF UK, Mlynska dolina F-2, Komenskeho Univerzita, SK-842 15 Bratislava, Slovakia

Dr. G.S. Lee, Korea Basic Science Institute, South Korea

Institute for Plasma Research, University of Maryland, USA

Librarian, Fusion Energy Division, Oak Ridge National Laboratory, USA

Librarian, Institute of Fusion Studies, University of Texas, USA

Librarian, Magnetic Fusion Program, Lawrence Livermore National Laboratory, USA

Library, General Atomics, USA

Plasma Physics Group, Fusion Energy Research Program, University of California at San Diego, USA

Plasma Physics Library, Columbia University, USA

Alkesh Punjabi, Center for Fusion Research and Training, Hampton University, USA

Dr. W.M. Stacey, Fusion Research Center, Georgia Institute of Technology, USA

Dr. John Willis, U.S. Department of Energy, Office of Fusion Energy Sciences, USA

Mr. Paul H. Wright, Indianapolis, Indiana, USA 
The Princeton Plasma Physics Laboratory is operated by Princeton University under contract with the U.S. Department of Energy.

\author{
Information Services \\ Princeton Plasma Physics Laboratory \\ P.O. Box 451 \\ Princeton, NJ 08543
}

Phone: 609-243-2750

Fax: 609-243-2751

e-mail: pppl_info@pppl.gov

Internet Address: http://www.pppl.gov 